\title{
Assessing the impact of race, social factors and air pollution on birth outcomes: a population-based study
}

\author{
Simone C Gray ${ }^{1 *}$, Sharon E Edwards², Bradley D Schultz ${ }^{1}$ and Marie Lynn Miranda ${ }^{2,3}$
}

\begin{abstract}
Background: Both air pollution exposure and socioeconomic status (SES) are important indicators of children's health. Using highly resolved modeled predictive surfaces, we examine the joint effects of air pollution exposure and measures of SES in a population level analysis of pregnancy outcomes in North Carolina (NC).

Methods: Daily measurements of particulate matter $<2.5 \mu \mathrm{m}$ in aerodynamic diameter $\left(\mathrm{PM}_{2.5}\right)$ and ozone $\left(\mathrm{O}_{3}\right)$ were calculated through a spatial hierarchical Bayesian model which produces census-tract level point predictions. Using multilevel models and NC birth data from 2002-2006, we examine the association between pregnancy averaged $\mathrm{PM}_{2.5}$ and $\mathrm{O}_{3}$, individual and area-based SES indicators, and birth outcomes.

Results: Maternal race and education, and neighborhood household income were associated with adverse birth outcomes. Predicted concentrations of $\mathrm{PM}_{2.5}$ and $\mathrm{O}_{3}$ were also associated with an additional effect on reductions in birth weight and increased risks of being born low birth weight and small for gestational age.

Conclusions: This paper builds on and complements previous work on the relationship between pregnancy outcomes and air pollution exposure by using 1) highly resolved air pollution exposure data; 2) a five-year population level sample of pregnancies; and 3) including personal and areal level measures of social determinants of pregnancy outcomes. Results show a stable and negative association between air pollution exposure and adverse birth outcomes. Additionally, the more socially disadvantaged populations are at a greater risk; controlling for both SES and environmental stressors provides a better understanding of the contributing factors to poor children's health outcomes.
\end{abstract}

Keywords: Air pollution, Exposure predictions, Pregnancy outcomes, Socioeconomic status

\section{Background}

Both air pollution exposure and socioeconomic status (SES) are important indicators of health, and particularly children's health. Studies have shown that adverse birth outcomes including low birth weight (LBW; birth weight $<2500 \mathrm{~g}$ ), small for gestational age (SGA; $<10$ th percentile of birth weight for gestational age), or preterm birth (PTB; $<37$ weeks of gestation) have been associated with lower SES $[1,2]$ and maternal exposure to air pollution [3-5]. Adverse birth outcomes are a major public health concern due to the association with increased risk

\footnotetext{
*Correspondence: simonegray@cdc.gov

'U.S. Environmental Protection Agency, Research Triangle Park, North Carolina, USA

Full list of author information is available at the end of the article
}

in neonatal mortality and both short- and long-term morbidity [6-9].

Environmental pollutants can have a disparate effect among economically disadvantaged and minority populations [10]. Studies have shown that these groups are also more likely to live in areas with higher levels of pollution, thus potentially detracting from their health [11-14]. A recent population-level analysis in North Carolina, showed that lower SES (income, poverty and education) and higher proportion minority populations (non-Hispanic black $[\mathrm{NHB}]$ and Hispanics) were associated with higher levels of particulate matter $<2.5 \mu \mathrm{m}$ in aerodynamic diameter $\left(\mathrm{PM}_{2.5}\right)$ [15]. Studies have also shown that the effects of pregnancy from air pollution exposure on NHB women are greater when compared to the effects on non-Hispanic white (NHW) women $[3,11]$.

\section{Biomed Central}


Air pollution exposure has also been associated with adverse birth outcomes for both NHB and NHW women $[5,16,17]$. Results from several studies have shown that higher levels of air pollution exposure have been associated with increased risk in LBW, SGA, and PTB $[4,11,18-20]$. Studies have also shown that there is a significant and persistent racial and socioeconomic disparity for a number of adverse pregnancy outcomes including infant mortality, LBW, PTB and intrauterine growth restriction (IUGR) [1,21-24]. Historically, infants born to NHB women have consistently lower birth weights than infants born to NHW women [25]. In 2010, the PTB rate for NHB was $16.9 \%$ compared to $10.8 \%$ for NHW and $11.8 \%$ for Hispanics [26]. For LBW, the prevalence for NHB was $13.5 \%$ compared to $7.1 \%$ and $7.0 \%$ for NHW and Hispanics [26]. Mothers living in low income neighborhoods and with lower levels of education are also at an increased risk for adverse birth outcomes [1,2,26,27].

Evidence has shown that there exists a relationship between SES and pregnancy outcomes [11,23,28,29], as well as SES and environmental exposures [30,31]. Because of these interrelated factors, care should be taken in trying to understand how both SES and air pollution jointly affect adverse birth outcomes. While individual-level social characteristics have been identified as risk factors for pregnancy outcomes, studies also suggest that neighborhoodlevel SES measures are also important $[2,19]$. Jointly studying the effects of individual- and area-level SES measures with air pollution on birth weight provides a more complete story of this important relationship.

As exact measures of personal air pollution exposure are both difficult and expensive to obtain, health studies often use measurements obtained from monitoring stations as surrogates for individual exposure assessment [3,5]. These collected measurements are obtained from a sparse network of monitoring stations and are not always collected on a daily basis, leading to large amounts of missing data. Alternatively, proximity to major roadways has also been used as a metric for individual air pollution exposures due to the large contribution of traffic emissions to ambient air pollution $[4,19,32,33]$. Other studies have explored the use of modeling techniques for estimating personal exposure including the Community Multi-Scale Air Quality Model (CMAQ), the probabilistic NAAQS Exposure Model (pCNEM), and the Stochastic Human Exposure and Dose Simulation Model (SHEDS-PM) [34-36]. In this study, we address the concern of missing data, both spatially and temporally, by using daily modeled predicted surfaces of air pollution as exposure inputs.

Our objective was to conduct a population level study of all pregnancies in North Carolina (NC) over a fiveyear period focusing on the effects of SES and air pollution. We assess the relationship between birth weight (BWT), LBW, SGA, and PTB and modeled air pollution measures. We use modeled predictive surfaces of $\mathrm{O}_{3}$ and $\mathrm{PM}_{2.5}$ to get daily concentration estimates at the census-tract level. This highly spatially resolved concentration metric is available for the entire state of $\mathrm{NC}$, which allows us to include women that would typically be excluded from analyses that use only monitoring networks as exposure surrogates. We obtain personal data from the North Carolina Detailed Birth Records (NCDBR) and neighborhood SES data from the US Census. We use both individual- and area-level measures of SES to capture the effects of the individual SES measures, as well as any additional residual area-level effects that may exist.

\section{Methods}

\section{Study population}

NCDBR data were obtained from the North Carolina State Center for Health Statistics for the years 2002-2006. The NCDBR contains birth outcomes, as well as maternal characteristics and demographics, for all registered live births in NC $(n=604,757)$. Infant characteristics obtained from the birth records included clinical estimate of gestational age (weeks), infant sex, BWT, indication of congenital anomalies, plurality, and date of birth. The maternal characteristics recorded in the NCDBR included residential address at time of birth, age, marital status, education, race and ethnicity, tobacco use, parity, and the trimester in which prenatal care began.

To link births from the NCDBR to the air pollution data, we used ArcGIS 9.3 software to geocode individual maternal residential street addresses at the street block level (ESRI, Redlands, CA). Approximately 14\% of the total births could not be successfully geocoded due to poor address information and were omitted from further analyses. We excluded multiple births (3.4\%), and infants with diagnosed congenital anomalies at the time of birth $(0.8 \%)$. These exclusions were chosen as we sought to focus on those pregnancies that could reasonably be expected to go to term and deliver at a normal BWT. We also excluded women $<15$ and $>44$ years of age $(0.3 \%)$ with more than 4 previous deliveries (3.8\%). Since $96 \%$ of the women in the dataset self-declared as NHW, NHB, or Hispanic, we excluded women of other races/ethnicities due to the small numbers in other minority groups. We excluded births with gestation $<24$ and $>42$ weeks $(0.1 \%)$, BWT $<400 \mathrm{~g}(0.2 \%)$, and mothers with any missing data on covariates $(1.0 \%)$, leaving 457,642 births. This study was conducted in accordance with a human subjects research protocol approved by the Duke University and University of Michigan Institutional Review Boards.

\section{Exposure measure}

Air pollution data from 2001-2006 were used as surrogate exposure measurements for this study, as exposure during pregnancy for some births in 2002 began in 2001. 
Using a Bayesian space-time downscaling fusion model, daily predicted $\mathrm{PM}_{2.5}$ (daily average in $\mu \mathrm{g} / \mathrm{m}^{3}$ ) and $\mathrm{O}_{3}$ (daily 8-hr maximum in $\mathrm{ppb}$ ) surfaces were obtained at the census tract level for the entire State of NC. Archived daily downscaler surfaces for 2001-2008 are available at: http:// www.epa.gov/esd/land-sci/lcb/lcb_faqsd.html. The downscaling fusion model uses input data from two sources: (1) monitoring networks and (2) numerical models. The air quality monitoring data came from the US Environmental Protection Agency Air Quality System repository database, and the numerical output came from the Models-3/Community Multiscale Air Quality (CMAQ; http://www.epa. gov/AMD/Research/RIA/cmaq.html). Further details and descriptions of the modeling approach can be found in Berrocal et al. [37].

To estimate air pollution exposure, we linked births to the census tract corresponding to each mother's residence at the time of delivery. The time period of exposure for each birth was calculated using the date of birth and the weeks of gestation at delivery, as recorded in the NCDBR. Using daily estimated pollution levels from the fused data, we calculated average exposure for the entire pregnancy. The high spatial and temporal resolution of the fused data provides exposure estimates for all of the successfully geocoded birth records, with no missing values for any days during the exposure window.

\section{SES data}

We use individual measures of SES from the NCDBR and an areal measure of household median income from the 2000 US Census. The size of census tracts in North Carolina ranges from 0.4 to $3529.6 \mathrm{sq} \mathrm{km}$ with a mean of 87.8 and a standard deviation (SD) of 171.3. Population density ranged from 2 to 4380 people per sq $\mathrm{km}$ with a mean of 442 and SD of 550. From the NCDBR, maternal education was categorized by years of completion as $<9$ (middle school), 9-11 (some high school), 12 (completed high school), 13-15 (some college), and > 15 years (completed college). We categorized the census tract-level household median income into tertiles as low, moderate, and high.

\section{Statistical analysis}

Linear and logistic mixed regression modeling were used to determine the association between exposure to the pollutants of interest, $\mathrm{O}_{3}$ and $\mathrm{PM}_{2.5}$, and an array of pregnancy outcomes. Using BWT (g) as a continuous outcome variable, we examined the effect of average $\mathrm{O}_{3}$ and $\mathrm{PM}_{2.5}$ over the entire pregnancy while controlling for gestational age (24-34, 35-36, 37-42 weeks), maternal race/ethnicity (NHB, NHW, or Hispanic), maternal education, maternal age at delivery $(15-19,20-24,25-29,30-34,35-39,40-$ 44 years), trimester prenatal care began, tobacco use during pregnancy (yes or no), marital status at delivery (married or unmarried), year of birth, parity (first birth, yes or no), infant sex, and census tract-level median household income. We also examined the effects of air pollution exposure on the binary outcomes of LBW, SGA, and PTB. SGA was calculated by comparing each record's birth weight and gestation age to a sex-specific, national reference distribution of birth weights for a given gestational age at delivery. Census tracts were specified as a random effect to account for neighborhood level correlation. Analyses were performed using SAS 9.3 (SAS Institute, Cary, NC).

\section{Results}

\section{Descriptive analysis}

Our analysis included 457,642 births after the exclusion criteria were applied. In the study population, $7.3 \%$ of births were LBW, $10.2 \%$ were SGA, and $9.8 \%$ were PTB. Table 1 shows the summary statistics for the entire study population and those with adverse birth outcomes. Our overall study population consisted mainly of women who were NHW (62\%), married (64\%), under 30 years of age $(66 \%)$, with at least a high school education (79\%), and living in moderate to high income census tracts (75\%). Approximately $12 \%$ of the women reported smoking during pregnancy.

Among births incurring a poor birth outcome, the proportion of births to mothers who were NHB and living in low household median income census tracts were greater than in the overall population of women. The largest difference between the demographic composition of the overall population and among births with adverse outcomes was seen among LBW births, where the proportion of NHB mothers rises from $23 \%$ in the general population to $50 \%$ among LBW births. Higher rates of firstborn births, women receiving no prenatal care, those who smoked during pregnancy, and mothers with lower educational attainment, all characteristics associated with poor birth outcomes, were seen among the poor birth outcomes subgroups compared to all births (Table 1).

Women with adverse birth outcomes had similar mean $\mathrm{PM}_{2.5}$ and $\mathrm{O}_{3}$ concentrations during pregnancy as the overall study population (Table 1). Mean air pollution levels for $\mathrm{PM}_{2.5}$ and $\mathrm{O}_{3}$ remain relatively consistent across race/ethnicity and the SES variables (results not shown). We observe a pairwise statistically significant relationship among the race/ethnicity, maternal education, and household median income variables, with $\mathrm{p}<.0001$ (data not shown).

\section{$\mathrm{PM}_{2.5}$ Multivariable analyses}

We calculated odds ratios (ORs) and 95\% confidence intervals (CI) for all birth outcomes. Table 2 displays the associations between race, $\mathrm{SES}$, and $\mathrm{PM}_{2.5}$ exposure and birth outcomes. NHB and Hispanic mothers were more likely to have infants born with lower birth weight when compared with NHW mothers $(-187.5 \mathrm{~g}, 95 \% \mathrm{CI}$ : -183.6 to -191.4 and $-46.8 \mathrm{~g}, 95 \% \mathrm{CI}:-41.8$ to -51.7 , respectively). 
Table 1 Demographics and clinical metrics of the study population overall and among births with adverse birth outcomes

\begin{tabular}{|c|c|c|c|c|}
\hline & All births $(n=457$ 642) & LBW (n = 30 458) & SGA $(n=42663)$ & PTB $(n=40746)$ \\
\hline Mean BWT in g (SD) & $3320.8(573.7)$ & $2003.1(508.0)$ & $2534.1(387.2)$ & $2392.6(717.0)$ \\
\hline \multicolumn{5}{|l|}{ Gestational age (\%) } \\
\hline 24-34 weeks & 3.3 & 43.3 & 4.3 & 37.2 \\
\hline 35-36 weeks & 5.6 & 25.0 & 7.6 & 62.8 \\
\hline 37-42 weeks & 91.1 & 31.7 & 88.0 & N/A \\
\hline Infant sex male (\%) & 51.2 & 46.9 & 50.3 & 53.2 \\
\hline First born (\%) & 42.7 & 50.9 & 52.5 & 45.7 \\
\hline \multicolumn{5}{|c|}{ Trimester prenatal care began (\%) } \\
\hline First & 84.9 & 81.0 & 79.6 & 83.2 \\
\hline Second & 12.6 & 15.0 & 16.7 & 12.4 \\
\hline Third & 1.9 & 1.9 & 2.6 & 2.1 \\
\hline None & 0.6 & 2.1 & 1.1 & 2.3 \\
\hline \multicolumn{5}{|l|}{ Year of birth (\%) } \\
\hline 2002 & 19.2 & 19.1 & 19.0 & 19.0 \\
\hline 2003 & 19.3 & 19.4 & 19.3 & 19.5 \\
\hline 2004 & 19.9 & 19.5 & 19.2 & 20.0 \\
\hline 2005 & 20.4 & 20.5 & 20.6 & 20.5 \\
\hline 2006 & 21.1 & 21.5 & 22.0 & 20.9 \\
\hline \multicolumn{5}{|l|}{ Race/ethnicity (\%) } \\
\hline Non-hispanic white & 62.4 & 39.0 & 48.2 & 57.5 \\
\hline Non-hispanic black & 22.8 & 50.2 & 37.7 & 31.2 \\
\hline Hispanic & 14.8 & 10.8 & 14.1 & 11.3 \\
\hline \multicolumn{5}{|l|}{ Maternal education (\%) } \\
\hline$<9$ years & 6.2 & 5.6 & 6.8 & 5.3 \\
\hline $9-11$ years & 15.0 & 21.2 & 22.5 & 17.4 \\
\hline 12 years & 28.4 & 33.1 & 33.3 & 30.7 \\
\hline $13-15$ years & 22.4 & 21.6 & 20.0 & 23.5 \\
\hline$>15$ years & 28.1 & 18.5 & 17.4 & 23.1 \\
\hline \multicolumn{5}{|l|}{ Maternal age (\%) } \\
\hline $15-19$ years & 11.4 & 16.4 & 17.8 & 13.5 \\
\hline $20-24$ years & 27.2 & 30.4 & 33.0 & 27.6 \\
\hline $25-29$ years & 27.2 & 23.8 & 23.7 & 25.3 \\
\hline $30-34$ years & 22.7 & 18.3 & 16.4 & 21.0 \\
\hline $35-39$ years & 9.9 & 9.1 & 7.6 & 10.5 \\
\hline 40-44 years & 1.7 & 2.0 & 1.6 & 2.2 \\
\hline Tobacco use (\%) & 11.7 & 21.0 & 22.2 & 15.5 \\
\hline Married (\%) & 64.4 & 49.7 & 48.1 & 58.1 \\
\hline \multicolumn{5}{|c|}{ Household median income (\$) } \\
\hline Mean (SD) & $424000(15490)$ & 39187 (13753) & $39284(14083)$ & 40605 (14403) \\
\hline \multicolumn{5}{|c|}{ Household median income (\%) } \\
\hline Low & 24.4 & 30.9 & 31.2 & 27.6 \\
\hline Moderate & 32.5 & 34.2 & 33.9 & 33.8 \\
\hline High & 43.1 & 34.9 & 34.9 & 38.6 \\
\hline
\end{tabular}


Table 1 Demographics and clinical metrics of the study population overall and among births with adverse birth outcomes (Continued)

\begin{tabular}{|c|c|c|c|c|}
\hline \multicolumn{5}{|l|}{$\overline{\mathrm{PM}_{2.5}\left(\mu \mathrm{g} / \mathrm{m}^{3}\right)}$} \\
\hline Mean (SD) & $13.6(1.7)$ & $13.6(1.8)$ & $13.7(1.7)$ & $13.6(1.8)$ \\
\hline Interquartile range & 2.0 & 2.3 & 2.0 & 2.3 \\
\hline \multicolumn{5}{|l|}{$\mathrm{O}_{3}$ in $\mathrm{ppb}$} \\
\hline Mean (SD) & $43.2(4.0)$ & $43.3(5.0)$ & $43.3(4.1)$ & $43.2(5.0)$ \\
\hline Interquartile range & 5.9 & 7.4 & 6.0 & 7.5 \\
\hline
\end{tabular}

Infants born to NHB mothers were also at an increased odds of being born LBW (adjusted OR 2.13, 95\% CI: 2.05 to 2.22 ), PTB (adjusted OR 1.46, 95\% CI: 1.42 to 1.50 ), and SGA (adjusted OR 2.18, 95\% CI: 2.12 to 2.24). In models for all outcomes, highly educated mothers and those living in high SES neighborhoods had better birth outcomes compared to mothers with only a high school level education and those living in moderate income neighborhoods (Table 2).

For the continuous BWT models, $\mathrm{PM}_{2.5}$ was associated with a small but significant reduction in BWT. An interquartile range (IQR) increase in $\mathrm{PM}_{2.5}$ during the entire gestational period reduced BWT by $3.1 \mathrm{~g}$ (95\% CI: 3.0 to 3.2). An IQR increase in maternal exposure to $\mathrm{PM}_{2.5}$ was significantly associated with increased odds of being SGA (adjusted OR 1.03, 95\% CI: 1.02 to 1.05$)$, but not LBW or PTB.

\section{$\mathrm{O}_{3}$ Multivariable analyses}

Table 3 displays the associations between race, SES, and $\mathrm{O}_{3}$ exposure and birth outcomes. Race and SES followed similar patterns to those seen in the $\mathrm{PM}_{2.5}$ models. NHB and Hispanic mothers were more likely to have infants born with lower birth weight when compared with NHW mothers $(-188.2 \mathrm{~g}, 95 \% \mathrm{CI}:-184.3$ to -192.1 and $-47.3 \mathrm{~g}$, 95\% CI: -42.4 to -52.3 , respectively). Infants born to NHB mothers were also at increased odds of being born LBW (adjusted OR 2.15, 95\% CI: 2.06 to 2.23), PTB (adjusted OR 1.46, 95\% CI: 1.43 to 1.51), and SGA (adjusted OR 2.20, 95\% CI: 2.14 to 2.26). Across all models, highly educated mothers and those living in census tracts with high household median income had better birth outcomes when compared to mothers with only a high school level education and those living in moderate income neighborhoods (Table 3).

Comparable to the $\mathrm{PM}_{2.5}$ results, the models for the continuous BWT outcomes showed a significant negative association with $\mathrm{O}_{3}$. An IQR increase in $\mathrm{O}_{3}$ during the entire gestational period reduced BWT by $7.4 \mathrm{~g}$ (95\% CI: 5.2 to 9.5). Additionally, an IQR increase in maternal exposure to $\mathrm{O}_{3}$ was significantly associated with increased odds

Table 2 Effects of Race/Ethnicity, SES and Fused PM 2.5 $_{2}$ on adverse birth outcomes ${ }^{a}$

\begin{tabular}{|c|c|c|c|c|}
\hline & $\begin{array}{c}\text { Birth weight } \\
\text { Change in grams }(95 \% \mathrm{Cl})\end{array}$ & $\begin{array}{c}\text { LBW } \\
\text { OR }(95 \% \mathrm{Cl}) \\
\end{array}$ & $\begin{array}{c}\text { SGA } \\
\text { OR }(95 \% \mathrm{Cl})\end{array}$ & $\begin{array}{c}\text { PTB } \\
\text { OR }(95 \% \mathrm{Cl}) \\
\end{array}$ \\
\hline \multicolumn{5}{|l|}{$\%$ Race/ethnicity } \\
\hline NHW & Reference & Reference & Reference & Reference \\
\hline $\mathrm{NHB}$ & $-187.5(-191.4,-183.6)$ & $2.13(2.05,2.22)$ & $2.18(2.12,2.24)$ & $1.46(1.42,1.50)$ \\
\hline Hispanic & $-46.8(-51.7,-41.9)$ & $0.99(0.93,1.05)$ & $1.21(1.17,1.26)$ & $0.78(0.75,0.81)$ \\
\hline \multicolumn{5}{|c|}{ \% Maternal education (years) } \\
\hline$<9$ & $-28.3(-35.1,-21.5)$ & $1.17(1.08,1.26)$ & $1.14(1.09,1.20)$ & $1.04(0.99,1.10)$ \\
\hline $9-11$ & $-33.1(-37.7,-28.5)$ & $1.19(1.14,1.25)$ & $1.15(1.12,1.19)$ & $1.08(1.05,1.12)$ \\
\hline 12 & Reference & Reference & Reference & Reference \\
\hline $13-15$ & $18.5(14.5,22.5)$ & $0.82(0.79,0.86)$ & $0.85(0.82,0.87)$ & $0.98(0.95,1.01)$ \\
\hline$>15$ & $31.6(27.2,36.0)$ & $0.72(0.68,0.75)$ & $0.72(0.69,0.75)$ & $0.78(0.75,0.80)$ \\
\hline \multicolumn{5}{|c|}{$\%$ Household median income } \\
\hline Low & $-7.5(-12.5,-2.5)$ & $1.04(1.00,1.08)$ & $1.04(1.00,1.07)$ & $1.01(0.98,1.04)$ \\
\hline Moderate & Reference & Reference & Reference & Reference \\
\hline High & $11.4(6.4,15.8)$ & $0.92(0.88,0.95)$ & $0.93(0.90,0.96)$ & $0.90(0.87,0.93)$ \\
\hline $\mathrm{PM}_{2.5}$ per IQR increase & $-3.13(-3.34,-2.93)$ & $1.02(0.99,1.04)$ & $1.03(1.02,1.05)$ & $1.01(0.99,1.02)$ \\
\hline
\end{tabular}

${ }^{a}$ Additional covaraites include gestational age (weeks), maternal age, trimester prenatal care began, tobacco use during pregnancy, marital status, year of birth, parity, and infant sex. 
Table 3 Effects of race/ethnicity, SES and fused $\mathrm{O}_{3}$ on adverse birth outcomes ${ }^{\mathrm{a}}$

\begin{tabular}{|c|c|c|c|c|}
\hline & $\begin{array}{c}\text { Birth weight } \\
\text { Change in grams }(95 \% \mathrm{Cl})\end{array}$ & $\begin{array}{c}\text { LBW } \\
\text { OR }(95 \% \mathrm{Cl})\end{array}$ & $\begin{array}{c}\text { SGA } \\
\text { OR }(95 \% \mathrm{Cl})\end{array}$ & $\begin{array}{c}\text { PTB } \\
\text { OR }(95 \% \mathrm{Cl})\end{array}$ \\
\hline \multicolumn{5}{|l|}{$\%$ Race/ethnicity } \\
\hline NHW & Reference & Reference & Reference & Reference \\
\hline $\mathrm{NHB}$ & $-188.2(-192.1,-184.3)$ & $2.15(2.06,2.23)$ & $2.20(2.14,2.26)$ & $1.46(1.43,1.51)$ \\
\hline Hispanic & $-47.3(-52.3,-42.4)$ & $0.99(0.93,1.05)$ & $1.22(1.18,1.27)$ & $0.78(0.75,0.81)$ \\
\hline \multicolumn{5}{|c|}{ \% Maternal education (years) } \\
\hline$<9$ & $-28.6(-35.4,-21.8)$ & $1.17(1.08,1.26)$ & $1.15(1.09,1.20)$ & $1.04(0.99,1.10)$ \\
\hline $9-11$ & $-33.1(-37.7,-28.5)$ & $1.19(1.14,1.25)$ & $1.15(1.12,1.19)$ & $1.08(1.05,1.12)$ \\
\hline 12 & Reference & Reference & Reference & Reference \\
\hline $13-15$ & $18.5(14.5,22.5)$ & $0.82(0.79,0.86)$ & $0.85(0.82,0.87)$ & $0.98(0.95,1.01)$ \\
\hline$>15$ & $31.1(26.7,35.5)$ & $0.72(0.68,0.76)$ & $0.72(0.70,0.75)$ & $0.78(0.75,0.80)$ \\
\hline \multicolumn{5}{|c|}{$\%$ Household median income } \\
\hline Low & $-7.6(-12.6,-2.6)$ & $1.04(1.00,1.09)$ & $1.03(1.00,1.07)$ & $1.01(0.98,1.04)$ \\
\hline Moderate & Reference & Reference & Reference & Reference \\
\hline High & $10.0(5.4,14.6)$ & $0.92(0.88,0.96)$ & $0.94(0.81,0.97)$ & $0.90(0.87,0.93)$ \\
\hline $\mathrm{O}_{3}$ per IQR increase & $-7.4(-9.5,-5.2)$ & $1.06(1.03,1.09)$ & $1.04(1.03,1.06)$ & $1.02(0.99,1.04)$ \\
\hline
\end{tabular}

of being SGA (adjusted OR 1.04, 95\% CI: 1.03 to 1.06) and LBW (adjusted OR 1.06, 95\% CI: 1.03 to 1.09), but not PTB.

\section{Sensitivity analyses}

Sensitivity analyses controlling for seasonality did not reveal season to be an important predictor of outcomes. Models adjusting for urban and rural indicators also did not modify the reported results. Interaction terms of SES and air pollution did not produce significant results for any of the adverse birth outcomes.

\section{Discussion}

We examined the effects of maternal exposure to $\mathrm{PM}_{2.5}$ and $\mathrm{O}_{3}$ and measures of SES on birth outcomes in NC. Our results indicate that both $\mathrm{O}_{3}$ and $\mathrm{PM}_{2.5}$ are associated with adverse birth outcomes, specifically LBW and SGA. As expected, individual and neighborhood SES also contribute to adverse birth outcomes. We found that NHB mothers and women with lower educational attainment were generally at an increased risk of having a poor birth outcome when compared to NHW mother and those with higher levels of education. Mothers living in census tracts with lower household median income were also at an increased risk of adverse pregnancy outcomes. Air pollution exposure contributed an additional harmful effect on pregnancy after controlling for race and individual and area-level SES.

Our findings on the association between adverse birth outcomes and $\mathrm{PM}_{2.5}$ are consistent with previous studies $[3,5,20]$. Using monitoring data from Connecticut and
Massachusetts, Bell et al. [3] showed reductions in BWT per IQR increase in $\mathrm{PM}_{2.5}$ during the entire pregnancy. In contrast to our study results, Bell et al. also showed increased odds of being born LBW for $\mathrm{PM}_{2.5}$. Gray et al. [5] used monitoring data in a previous North Carolina study and showed reductions in BWT for $\mathrm{PM}_{2.5}$.

While a number of studies have examined the relationship between particulate matter and pregnancy, fewer studies have focused on $\mathrm{O}_{3}$, and fewer still have found a consistent and significant relationship with adverse pregnancy outcomes [20,38,39]. A recent study in Texas found a negative effect on BWT per IQR increase of $\mathrm{O}_{3}$ during the entire gestational period [40]. Salam et al. [35] showed similar results for $\mathrm{O}_{3}$ and BWT in a California study. Liu et al. [41] found no statistically significant results for $\mathrm{O}_{3}$ and PTB or LBW in Vancouver, Canada.

This study is not without limitations. We acknowledge that the modeled concentration data for $\mathrm{O}_{3}$ and $\mathrm{PM}_{2.5}$ are not explicit measures of maternal exposure to pollution, as they do not take into account daily activity patterns, indoor sources, or ventilation conditions. We also used maternal address at the time of delivery, which may not necessarily be the address during the entire pregnancy. Data on residential mobility were not available for this study. These results may also be affected by residual confounding as there are several other factors we were unable to control for that can contribute to pregnancy outcomes, including access to healthcare, prepregnancy weight, maternal height, and nutrition.

One of the key strengths of this study is the availability of exposure data for the entire State of NC with no missing 
days of exposure data. In environmental health studies, air pollution measurements from a sparse network of monitoring stations or proximity to major roadways are commonly used as a proxy for personal exposure. The fine spatial and temporal resolution of the modeled air pollution data allowed us to obtain estimates for times and locations where exposure data are not otherwise available. With air pollution estimates for the entire state, the analyses were performed at the population level rather than in a non-randomly restricted subset of the population based on proximity to environmental hazards or monitoring stations.

Previous studies have used hierarchical models to examine the relationship between individual and local SES, pollution, and adverse birth outcomes, but many focus on traffic-related pollution, proximity to highways, lead, or sulfur dioxide $[18,19,42,43]$. Our study, on the other hand, uses a multi-level structure to incorporate individual and neighborhood level SES factors along with modeled concentration data for $\mathrm{PM}_{2.5}$ and $\mathrm{O}_{3}$.

The biological mechanisms through which air pollution may affect pregnancy are still unclear. Air pollution may affect birth outcomes through multiple pathways including oxidative stress, blood flow, placental formation and function, and inflammatory responses [44]. Additional factors that can also influence this relationship include the timing of the air pollution exposure, the pollutant and the birth outcome of interest [45]. Recent studies have examined the relationship between air pollution and pregnancy outcomes using animal models. Evidence suggests that prenatal exposures to air pollution in mice can impair fetal lung growth and increase both airway hyper-responsiveness and infiltration of inflammatory cells [46,47]. Another mouse study showed that exposure during pregnancy to $\mathrm{O}_{3}$ affected both lung function and reproductive outcomes in the offspring [48]. Increased $\mathrm{O}_{3}$ exposure was associated with decreases in the number of viable pregnancies and the body weight in the surviving offspring [48]. More work on examing the biological pathways is critical in understanding the association between air pollution and adverse birth outcomes.

\section{Conclusions}

This study on infant health uses modeled state-wide measurements of air pollution along with individual and neighborhood SES in a hierarchical model on pregnancy outcomes. Our results show that despite NC's consistent attainment of federal air quality standards, there is a stable and negative association between air pollution exposure and adverse birth outcomes. Additionally, the more socially disadvantaged populations are at a greater risk, and controlling for both SES and environmental stressors provides a better understanding of the factors contributing to reproductive health.

\section{Abbreviations}

BWT: Birth weight; Cl: Confidence interval; CMAQ: Community Multi-Scale Air Quality Model; IUGR: Intrauterine growth restriction; LBW: Low birth weigh; NC: North Carolina; NCDBR: North Carolina Detailed Birth Records; NHB: Non-Hispanic Black; NHW: Non-Hispanic White; $\mathrm{O}_{3}$ : Ozone; OR: Odds ratio; pCNEM: Probabilistic NAAQS Exposure Model; PM2.5: Particulate matter $<2.5 \mu \mathrm{m}$ in aerodynamic diameter; PTB: Preterm birth; SES: Socioeconomic status; SGA: Small for gestational age; SHEDS-PM: Stochastic human exposure and dose simulation model.

\section{Competing interests}

The authors declare that they have no competing interests.

\section{Authors' contributions}

SCG participated in the original study design, carried out the primary data analysis, and prepared the first draft of the manuscript. SEE coordinated the data collection and participated in the manuscript preparation. BDS and MLM made substantial contributions to the design and direction of the study. All authors assisted with drafting and revising the manuscript. All authors have read and approved the final manuscript.

\section{Acknowledgements}

We thank Claire Osgood and Nancy Schneider for helpful data management support.

Marie Lynn Miranda and Sharon Edwards were supported by funding from the US Environmental Protection Agency (RD-83329301-0).

\section{Author details}

${ }^{1}$ U.S. Environmental Protection Agency, Research Triangle Park, North Carolina, USA. ${ }^{2}$ Children's Environmental Health Initiative, School of Natural Resources and Environment, University of Michigan, Ann Arbor, Michigan, USA. ${ }^{3}$ Department of Pediatrics, University of Michigan, Ann Arbor, Michigan, USA.

Received: 27 March 2013 Accepted: 31 July 2013

Published: 29 January 2014

\section{References}

1. Subramanian SV, Chen JT, Rehkopf DH, Waterman PD, Krieger N: Comparing individual-and area-based socioeconomic measures for the surveillance of health disparities: a multilevel analysis of Massachusetts births, 1989-1991. Am J Epidemiol 2006, I 64:823-834.

2. Luo Z-C, Wilkins R, Kramer MS: Effect of neighborhood income and maternal education on birth outcomes: a population-based study. Can Med Assoc J 2006, 174:1415-1421.

3. Bell ML, Ebisu K, Belanger K: Ambient air pollution and low birth weight in Connecticut and Massachusetts. Environ Health Perspect 2007, 115:1118-1124.

4. Miranda ML, Edwards SE, Chang HH, Auten RL: Proximity to roadways and pregnancy outcomes. J Expo Sci Environ Epidemiol 2013, 23:32-38.

5. Gray SC, Edwards SE, Miranda ML: Assessing exposure metrics for PM and birth weight models. J Expo Sci Environ Epidemiol 2010, 20:469-477.

6. Terzidou V, Bennett PR: Preterm labour. Curr Opin Obstet Gynecol 2002, 14:105-113.

7. Hack M, Klein NK, Taylor HG: Long-term developmental outcomes of low birth weight infants. Future Child 1995, 5:176-196.

8. Lucas JS, Inskip HM: Small size at birth and greater postnatal weight gain: relationships to diminished infant lung function. Am J Respir Crit Care Med 2004, 170:534-540.

9. Barker DJP, Gluckman DP, Godfrey KM, Harding JE, Owens JA, Robinson JS: Fetal nutrition and cardivascular disease in later life. Lancet 1993, 341:938-941.

10. Sexton K, Gong H, Bailar JC, Ford JG, Gold DR, Lambert WE, Utell MJ: Air pollution health risks: do class and race matter? Toxicol Ind Health 1993, 9:843-878.

11. Woodruff TJ, Parker JD, Kyle AD, Schoendorf KC: Disparities in exposure to air pollution during pregnancy. Environ Health Perspect 2003, 111:942-946.

12. Gwynn RT, George: The burden of air pollution: impacts among racial minorities. Environ Health Perspect 2001, 109:501-506. 
13. Perlin S, Wong D, Sexton K: Residential proximity to industrial sources of air pollution: interrelationships among race, poverty, and age. J Air Waste Manag Assoc 2001, 51:406-421.

14. Yanosky JD, Schwartz J, Suh HH: Associations between measures of socioeconomic position and chronic nitrogen dioxide exposure in Worcester, Massachusetts. J Toxicol Environ Health A 2008, 71:1593-1602.

15. Gray SC, Edwards SE, Miranda ML: Race, Socioeconomic Status, and Air Pollution Exposure in North Carolina. Environ Res 2013, 126:152-158.

16. Bobak M: Outdoor air pollution, low birth weight, and prematurity. Environ Health Perspec 2000, 108:173-176.

17. Dugandzic R, Dodds L, Stieb D, Smith-Doiron M: The association between low level exposures to ambient air pollution and term low birth weight: a retrospective cohort study. Environ Health 2006, 5:3.

18. Zeka A, Melly SJ, Schwartz J: The effects of socioeconomic status and indices of physical environment on reduced birth weight and preterm births in Eastern Massachusetts. Environmental: Health; 2008:7

19. Genereux M, Auger N, Goneau M, Daniel M: Neighbourhood socioeconomic status, maternal education and adverse birth outcomes among mothers living near highways. J Epidemiol Community Health 2008, 62:695-700

20. Ha E-H, Hong Y-C, Lee B-E, Woo B-H, Schwartz J, Christiani DC: Is air pollution a risk factor for low birth weight in Seoul? Epidemiology 2001, 12:643-648.

21. Singh GK, Yu SM: Infant mortality in the United States: trends, differentials, and projections, 1950 through 2010. Am J Public Health 1995, 85:957-964.

22. Parker JD, Schoendorf KC, Kiely JL: Associations between measures of socioeconomic status and low birth weight, small for gestational age, and premature delivery in the United States. Ann Epidemio/ 1994, 4:271-278.

23. Kogan MD: Social causes of low birth weight. J R Soc Med 1995, 88:611-615

24. Krieger N: Epidemiology, racism, and health: the case of low birth weight. Epidemiology 2000, 11:237-239.

25. Martin JA, Hamilton BE, Ventura SJ, Osterman MJ, Kirmeyer S, Mathews TJ, Wilson EC: Births: Final Data for 2009. National Vital Statistics Report 2011, 60. Hyattsville, MD: National Center for Health Statistics.

26. Martin JA, Hamilton BE, Ventura SJ, Osterman MJK, Wilson EC, Mathews TJ: Births: final data for 2010. In Edited by Report NVS. Hyattsville, MD: National Center for Health Statistics; 2012.

27. Kramer MS, Seguin L, Lydon J, Goulet L: Socio-economic disparities in pregnancy outcome: why do the poor fare so poorly? Pediatr Perinat Epidemiol 2000, 14:194-210.

28. Andersen A-MN, Mortensen LH: Socioeconomic inequality in birth outcomes: what do the indicators tell us and where do we find the data? Can Med Assoc J 2007, 174:1429-1430.

29. Weck RL, Paulose T, Flaws JA: Impact of environmental factors and poverty on pregnancy outcomes. Clin Obstet Gynaecol 2008, 51:349-359.

30. Mitchell R, Popham F: Effect of exposure to natural environment on health inequalities: an observational population study. Lancet 2008, 372:1655-1660.

31. Lee AC, Maheswaran R: The health benefit of urban green spaces: a review of the evidence. J Public Health (Oxf) 2011, 33:212-222.

32. Karr CJ, Rudra CB, Miller KA, Gould TR, Larson T, Sathyanarayana S, Koenig JQ: Infant exposure to fine particulate matter and traffic and risk of hospitalization for RSV bronchiolitis in a region with lower ambient air pollution. Environ Res 2009, 109:321-327.

33. Hart JE, Laden F, Puett RC, Costenbader KH, Karlson EW: Exposure to traffic pollution and increased risk of rheumatoid arthritis. Environ Health Persect 2009, 117:1065-1069.

34. Zidek JV, Meloche J, Chatfield C, White R: A computational model for estimating personal exposure to air pollutants with application to London's $P M_{10}$ in 1997. Technical Report of the Statistical and Applied Mathematical Sciences Institute; 2003.

35. Zidek JV, Shaddick G, Chatfield C, White R: A framework for predicting personal exposures to environmental hazards. Environ Ecol Stat 2007, 01:411-431.

36. Berrocal VJ, Gelfand AE, Miranda ML, Holland D, Burke J: On the use of a $\mathrm{PM}_{2.5}$ exposure simulator to explain birthweight. Environ Sci Technol 2010, 22:553-571.

37. Berrocal VJ, Gelfand AE, Holland DM: A spatio-temporal downsscaler for output from numerical models. J Agri Biol Environ Stat 2010, 15:176-197.

38. Salam MT, Millstein J, Li YF, Lurmann FW, Margolis HG, Gilliland FD: Birth outcomes and prenatal exposure to ozone, carbon monoxide, and particulate matter: results from the Children's Health Study. Environ Health Perspect 2005, 113:1638-1644.

39. Currie J, Neidell M, Schmieder JF: Air pollution and infant health: Lessons from New Jersey. J Health Econ 2009, 28:688-703.

40. Geer LA, Weedon J, Bell ML: Ambient air pollution and term birth weight in Texas from 1998 to 2004. J Air Waste Manag Assoc 2012, 62:1285-1295.

41. Liu S, Krewski D, Shi Y, Chen Y, Burnett RT: Association between gaseous ambient air pollutants and adverse pregnancy outcomes in Vancouver, Canada. Environ Health Perspect 2003, 111:1773-1778.

42. Williams BL, Pennock-Roman M, Suen HK, Magsumbol MS, Ozdenerol E: Assessing the impact of the local environment on birth outcomes: a case for HLM. J Expo Sci Environ Epidemiol 2007, 17:445-457.

43. Ponce NA, Hoggatt KJ, Wilhelm M, Ritz B: Preterm birth: the interaction of traffic-related air pollution with economic hardship in Los Angeles nieghborhoods. Am J Epidemiol 2005, 162:140-148.

44. Kannan S, Misra DP, Dvonch JT, Krishnakumar A: Exposures to airborne particulate matter and adverse perinatal outcomes: a biologically plausible mechanistic framework for exploring potential effect modification by nutrition. Environ Health Persect 2006, 114:1636-1642.

45. Shah PS, Balkhair T: Air pollution and birth outcomes: a systemic review. Environ Int 2011, 37:498-516.

46. Fedulov AV, Leme A, Yang Z, Dahl M, Lim R, Mariani TJ, Kobzik L: Pulmonary exposure to particles during pregnancy causes increased neonatal asthma susceptibility. Am J Respir Cell Mol Biol 2008, 38:57-67.

47. Auten RL, Gilmour MI, Krantz QT, Potts EN, Mason SN, Foster WM: Maternal diesel inhalation increases airway hyperreactivity in ozone exposed offspring. Am J Respir Cell Mol Biol 2012, 46:454-460.

48. Sharkhuu T, Doerfler DL, Copeland C, Luebke RW, Gilmour Ml: Effect of maternal exposure to ozone on reproductive outcomes and immune inflammatory, and allergic responses in the offspring. $J$ Immunotoxicol 2011, 8:183-194.

doi:10.1186/1476-069X-13-4

Cite this article as: Gray et al:: Assessing the impact of race, social factors and air pollution on birth outcomes: a population-based study. Environmental Health 2014 13:4

\section{Submit your next manuscript to BioMed Central and take full advantage of:}

- Convenient online submission

- Thorough peer review

- No space constraints or color figure charges

- Immediate publication on acceptance

- Inclusion in PubMed, CAS, Scopus and Google Scholar

- Research which is freely available for redistribution

Submit your manuscript at www.biomedcentral.com/submit
C) Biomed Central 